\title{
0 Cândido de Voltaire: militância e melancolia
}

\author{
Maria das Graças de Souza \\ mgs@usp.br \\ Universidade de São Paulo, São Paulo, Brasil
}

resumo Trata-se aqui de interpretar algumas passagens do Cândido no quadro das linhas de força do iluminismo francês, que dizem respeito ao modo de conceber a atividade do filósofo, orientado pela oposição entre as figuras do "filósofo de gabinete" e o "filósofo mundano." Do meu ponto de vista, esta oposição não encerra tão somente uma tomada de posição sobre a natureza da ação do filósofo, mas diz respeito mesmo a uma concepção do que é a "boa filosofia." Ao mesmo tempo, permitirá uma interpretação da famosa metáfora do jardim do final do Cândido à luz da concepção voltaireana da história.

palavras-chave Filosofia; Engajamento; Ilustração; Candide; Filosofia da história.

Tomemos a distinção, muito comum nas Luzes, entre o filósofo de gabinete e o filósofo homem do mundo. O filósofo de gabinete é bem representado por Descartes, que, ao pé da lareira, vestido em robe de chambre, reconstrói, por assim dizer, o mundo, tal como vemos nas Meditações. No parágrafo 2 da primeira meditação, Descartes diz que depois de muito tempo, decidiu-se então a empreender sua tarefa de buscar um fundamento sólido para as ciências, agora que se sentia com "o espírito livre de cuidados" e tendo um "repouso assegurado numa pacífica solidão" (DESCARTES, 1996a, p. 13). No Discurso do método, Descartes afirma que não quer ser acusado de ser como os espíritos inquietos, de temperamento perturbador, que querem praticar reformas no mundo, e que seu intento nunca foi além de procurar reformar meus próprios pensamentos e construir num terreno que é todo seu (DESCARTES 1996b, p. 15). 
Guardemos estas metáforas: a lareira, a despreocupação com os cuidados da vida, o repouso e a solidão, a reforma pessoal, o guia para caminhar na vida.

Ora, o filósofo das luzes é um espírito inquieto que recusa a solidão. (a não ser que sejam forçados a ela, o que de fato aconteceu:Voltaire teve passagens pela Bastilha e algumas fugas e exílios, o último deles de mais de vinte anos, Diderot uma passagem pela prisão de Vincennes). Ele se pensa como homem do mundo não apenas no sentido das suas relações sociais (frequenta os salões, vai às exposições de arte, ao teatro, aos recitais de música, aprecia o conforto e as comodidades da vida), mas do ponto de vista mesmo do lugar em que ele fala, e do público a quem se dirige. Ele filosofa, como diz Voltaire no Dicionário Filosófico, na arena. Quer dizer: não somente em posição visível, mas também em posição de combate.

Tomemos então esta figura do filósofo como homem do mundo tal como ela aparece no verbete Philosophe da Encyclopédie. A razão, que lhe dá justeza de espírito para bem julgar as coisas, exige dele, nas palavras de Diderot, autor do verbete, "que conheça, que estude, que trabalhe para adquirir qualidades sociais.” (DIDEROT et D’ALEMBERT, 1751-1765, "Philosophe"). Ele não se vê como alguém em exílio no mundo, não crê que esteja em país inimigo quando está entre os outros; é, para citar novamente o verbete, "um homem honesto que quer agradar e ser útil." Adota para si a máxima de Terêncio: sou homem, e tudo o que é humano me concerne.

Esta tomada de posição, de sentir-se concernido por tudo o que diz respeito ao mundo dos homens e à posteridade (e que faz lembrar de algum modo, a ideia de responsabilidade pelo mundo em Hannah Arendt), esta tomada de posição, digo, é o núcleo mesmo do projeto enciclopédico.

Esta tomada de posição incide, em primeiro lugar, sobre a forma da escrita filosófica: embora possamos identificar algumas obras escritas na forma de tratados tradicionais, as ideias filosóficas são formuladas em romances, peças de teatro, dicionários, contos, diálogos, sátiras. Isto não significa apenas que os filósofos querem escrever de modo a garantir o acesso de um público maior e não especializado às ideias que querem difundir. Significa isto também, não se pode negar. Mas não é só isto. Esta diversidade de escritos que tomam emprestada a forma de outros gêneros está ligada diretamente ao fato de que a filosofia entendida como pensamento 
engajado ou comprometido implica numa relação com a cultura como um todo, com as artes, com a história, com a literatura, com as produções do espírito humano. A filosofia das luzes não se pensa ela mesma como um saber técnico especializado independente dos outros saberes, nem independente dos fazeres. E a atividade do filósofo não é tão somente a busca da verdade, mas também o diagnóstico de seu tempo e a reflexão sobre a ação.

No caso de Voltaire, isto nos leva, em primeiro lugar, ao seu combate ao que denominava a Infame. O que é a "infame”? É um monstro de muitas faces: a ignorância, que embrutece os homens, o fanatismo religioso, a intolerância de todo tipo, o entusiasmo missionário, o furor teológico, as restrições à liberdade de pensamento, a tortura, as prisões arbitrárias. Voltaire escreveu para a Enciclopédia o verbete "homem de letras", no qual associa o que ele chama de "espírito filosófico" com o que nós chamamos de intervenção. Numa das passagens do verbete, eu cito, diz Voltaire que "uma das grandes vantagens de nosso século é que o número de homens instruídos que passam dos espinhos da matemática às flores da poesia, e julgam igualmente bem um livro de metafisica e uma peça de teatro: o espírito do século tornou-os, em sua maioria, adequados ao mundo e ao gabinete. E é nisto que eles são superiores aos dos séculos precedentes. [...].Esta razão aprofundada e purificada, que muitos difundiram em seus escritos e em suas conversações, muito contribuiu para instruir e polir a nação. Sua crítica não mais se consumiu em palavras gregas e latinas; mas, apoiada por uma sã filosofia, ela destruiu todos os preconceitos que infestavam a sociedade: previsões dos astrólogos, adivinhações dos mágicos, sortilégios de toda espécie, falsos prodígios, falsas maravilhas, costumes supersticiosos; ela relegou às escolas mil disputas pueris que outrora foram perigosas e que eles tornaram desprezíveis: com isto, eles serviram ao Estado.” (DIDEROT et D'ALEMBERT, 1751-1765, “Gens de lettres”).

É fácil reencontrar o tema nos outros textos de Voltaire. Por exemplo, nas Reflexões para os tolos, lemos que "se o mundo vai um pouco melhor", é porque os filósofos "ridicularizaram a tolice de nossos pais, de sorte que hoje é impossível ser tão tolos quanto eles.” (VOLTAIRE, 1965, p. 355). No texto Ideias republicanas, Voltaire se pergunta: "será que conseguiremos tornar os homens melhores por meio de livros que destroem a superstição e tornam a virtude amável?” A resposta é sim; “se os jovens leem 
estes livros com atenção, serão preservados de toda espécie de fanatismo; sentirão que a paz é o fruto da tolerância e que o verdadeiro fim de nossa sociedade." (VOLTAIRE, 1965, p. 524). E na Advertência sobre os parricídios imputados aos Calas e aos Sirven, dentre os "remédios contra o furor das almas", Voltaire recomenda a leitura de Cícero, de Sêneca, e seu próprio poema sobre a lei natural (VOLTAIRE, 1965, p. 847).

Perguntamos então se esta perspectiva está presente no Cândido. Não exatamente. É certo que Cândido é, de início, um aprendiz de filosofia. Mas de uma filosofia, para usar o termo de Hume, "abstrusa". De qualquer modo, isto não impede seu entusiasmo pelo sistema de Pangloss, "oráculo da casa, o maior filósofo da província, e, por consequência, de toda a terra", que ensinava "metafisico-teologo-nigologia", a quem ele "ouvia atentamente", em que ele "acreditava inocentemente", e de cujo fascínio, como sabemos, ele vai se libertar com muita dificuldade (VOLTAIRE, 1967a, p.150).

Esta libertação não se dará precisamente por meio da leitura; o esclarecimento do aprendiz de filósofo dar-se-á por meio da experiência brutal do mundo. A descrição destes males é ao mesmo tempo um diagnóstico de seu tempo: a desigualdade social (Cândido é filho bastardo na família, mas mantido como criado); a violência física (o próprio Cândido, a história da velha); a guerra (o episódio entre os soldados búlgaros e dos ábaros); a intolerância religiosa, em vários episódios; o poder e a corrupção do clero, a inquisição e o auto-da-fé em Lisboa; a colonização; a escravidão negra, etc. A sua primeira meditação não é a da dúvida metódica, pois não se trata da dúvida em relação à consistência propriamente filosófica do otimismo de matriz leibniziana, mas da dúvida em relação à capacidade do sistema do mestre em dar conta da realidade do mundo.

Mas, mesmo no que tange ao que seria a boa filosofia, ou a sã filosofia, na expressão de Voltaire, as coisas não são tão simples. Em várias passagens de seus textos, há uma manifestação de descrença, se não de negação mesmo, de que a ação do filósofo possa mudar alguma coisa no mundo.

Vejamos algumas destas passagens. Primeiro: o filósofo não costuma interferir nos costumes. "Quando, outrora, diz Voltaire, se levava o relicário de Santa Genoveva pelas ruas de Paris, para pedir chuva ou bom tempo, nenhum filósofo perturbou a procissão, e quando os convulsionários pediam os santos auxílios, nenhum filósofo os atacou com pauladas." 
(VOLTAIRE, 1965, p. 355). Em seguida, o filósofo não se intromete em querelas que não são de sua alçada: “quando os jesuítas, diz Voltaire, empregaram a calúnia, as confissões e as lettres de cachet contra todos aqueles que acusavam de serem jansenistas, ou seja, de serem seus inimigos, ou quando os jansenistas se vingaram como puderam das insolentes perseguições dos jesuítas, os filósofos não se intrometeram de modo algum nestas querelas.” (VOLTAIRE, 1965, pp. 354-355).

Em segundo lugar, o filósofo não faz mal a ninguém. "Alguma vez, eu cito Voltaire, “ já se viram filósofos trazer a guerra, a fome ou a peste a um país? Bayle, por exemplo... alguma vez pensou em quebrar os diques da Holanda para afogar seus habitantes, como pensava um grande ministro que não era filósofo?”(VOLTAIRE, 1965, p. 459). Em O filósofo ignorante, lemos o seguinte: "Cá entre nós, diga-me se um filósofo causou a menor perturbação à sociedade... Não são eles, na maioria, solitários? Não são pobres, sem proteção, sem apoio?... estes pobres diabos alguma vez disputaram convosco vossos empregos, vossas prerrogativas, vossos tesouros? Muitos disseram tolices, é verdade. Mas suas quimeras nunca acenderam guerras civis." (VOLTAIRE, 1965, p. 900).

O filósofo, assim, não tem poder algum. “... nenhum filósofo teve influência alguma nem sobre os costumes da própria rua em que morava. Por quê? Porque os homens se conduzem pelos costumes e não pela metafisica. Um só homem eloquente, hábil, e acreditado, terá muito poder sobre os homens; cem filósofos não terão nenhum poder, se forem tão somente filósofos." (VOLTAIRE, 1965, p. 900).

Enfim, o filósofo não é nenhum perturbador da ordem. "A perseguição contra os homens que pensam não vem da crença de que eles são perigosos, pois certamente nenhum deles jamais conseguiu fazer com que quatro patifes se amotinassem na Place Maubert, nem na grande sala. Nenhum filósofo falou com Jacques Clément, nem com Barrièrre, nem com Chatel, Ravaillac, ou Damiens.” (VOLTAIRE, 1965, p. 354). Todos estes personagens foram autores de atentados políticos: Jacques Clement, monge regicida que assassinou o rei Henrique III em 1589; Barrièrre, que tentou assassinar Henrique IV. Chatel também tentou assassinar o mesmo rei. Ravaillac é o assassino de Henrique IV. Damiens deu uma facada em Luís XV.

Então, o filósofo não consegue ter influência nem sobre seus vizinhos. Mas ele continua a fazer a guerra à direita, à esquerda, recebe 


\section{4}

estocadas, devolve outras, e ri, como diz em sua correspondência. Para uns, como diz a D’Alembert numa carta, “carrega seu fuzil com sal, para outros, com balas bem grandes." De longe, ele diz na mesma carta, lança fogos de artificio sobre a cabeças dos outros, e ri mais ainda. Ele se autodenomina grande demolidor, e às vezes escreve ameaças explícitas, como nesta passagem do verbete "Abade", do Dicionário Filosófico: "Todos vocês que se aproveitaram dos tempos de ignorância, de superstição e de demência para nos espoliar, nos pisotear, para engordar às custas dos infelizes, tremam de medo, quando o dia da razão chegar." (VOLTAIRE, 1967b, p. 2).

A questão é precisamente a de saber como conciliar aquela espécie de atitude melancólica segundo a qual a ação do filósofo é inútil e nem é percebida pelos homens, com o vigor do filósofo que, como ele mesmo diz, "escreve para agir". Do ponto de vista dos contos, nota-se também um traço melancólico: no Micrômegas, Voltaire apresenta o homem como um inseto insignificante que mora num ponto minúsculo do universo infinito (VOLTAIRE, 1967a, p. 117). No Ingênuo, as desventuras do jovem índio canadense não servem para nada. Ele conseguiu tornar-se um oficial filósofo, mas até o fim de seus dias, como narra o conto, ele lamentará a perda da Senhorita Saint-Yves (VOLTAIRE, 1967a, p.301). Nas cenas finais do Zadig, o anjo Jesrad parece que vai poder decifrar o enigma do mundo, mas enquanto Zadig pergunta, o anjo já está longe em seu voo para o céu (VOLTAIRE, 1967a, p. 62).

Quanto ao Cândido, se o considerarmos como uma aventura de formação, o que Cândido aprendeu? Que se está igualmente mal em toda a parte. Os personagens que sobreviveram ao amontoado de males ficaram feios, gordos, implicantes e com suas manias agravadas. O que fazer então? Há o diálogo com o dervixe, que termina com a passagem sobre os ratos no porão de um navio, de cujo bem estar o comandante não se ocupa. Durante a conversa, chegam novas notícias sobre catástrofes no mundo. Voltando para casa, Cândido encontra um ancião, que lhe diz o seguinte: "Presumo que os que se intrometem nos negócios públicos às vezes perecem miseravelmente, e merecem isto." (VOLTAIRE, 1967a, p. 236). Assim, a filosofia, não somente não é boa para nada, bem como a tentativa de interferir nos acontecimentos pode ter maus resultados. Vem então o elogio final do cultivo do jardim. 
O abandono da discussão filosófica e o convite para o cultivo do jardim têm sido interpretados das maneiras mais diversas pela tradição crítica. O que proponho aqui é uma interpretação à luz da filosofia da história de Voltaire.

Tomemos então a metáfora. Em princípio, o cultivo do jardim remete à oposição entre natureza e artifício, ou em termos mais contemporâneos, entre natureza e cultura. Neste sentido, cultivar é obra da civilização. Com todo o cuidado que devemos ter com o termo civilização, cujo uso é raro e tardio no século XVIII, cultivar nosso jardim significa assumir a tarefa civilizadora. Assim, o conto, ao denunciar a barbárie, faz o elogio da civilização. Mas as coisas não são tão simples assim, porque a barbárie que cai sobre Cândido e sobre os outros personagens ocorre no seio mesmo da civilização, na Europa cultivada, sobretudo.

Deste modo, da ficção, passamos à filosofia voltaireana da história. Há um lugar comum muito difundido a respeito de Voltaire segundo o qual ele é visto como o profeta, ou apóstolo do progresso. De fato, o elogio de Voltaire ao século XVII, chamado o século de Luís XIV, vai neste sentido. Entretanto, é preciso assinalar que, mesmo neste elogio do grande século, Voltaire dedica boa parte da obra para mostrar o que teria sido o que poderíamos chamar de as sombras do reino do rei sol: a perseguição aos jansenistas, aos protestantes, as guerras, sinais de uma barbárie manifesta no interior mesmo da civilização. A perspectiva que Voltaire apresenta no Ensaio sobre os costumes também não é muito diferente. Lemos, no Ensaio, o seguinte: "É fácil observar que os costumes mudaram em quase toda a terra desde as invasões bárbaras até nossos dias. As artes, que amenizam os espíritos ao esclarecê-los, começaram a renascer um pouco desde o século XII; mas, as mais covardes e absurdas superstições, sufocando este germe, embruteciam todos os espíritos; e estas superstições, espalhando-se por todos os povos da Europa, ignorantes e ferozes, juntavam, em todos os lugares, o ridículo e a barbárie... Deve-se pois confessar que toda esta história é um amontoado de crimes, de loucuras, e de infelicidades, no meio das quais se podem ver algumas virtudes, alguns tempos felizes, como se fossem habitações espalhadas aqui e ali no meio de desertos selvagens." (VOLTAIRE, 1990, t.II, p. 802).

O que é a barbárie para Voltaire? São as prisões forçadas, as condenações sem defesa, a tortura, os confinamentos em mosteiros, os assassinatos, 
os suplícios, os duelos, tudo o que ameaça a vida, e também as fraudes, religiosas ou políticas, a justiça sumária, a delação, a censura, o abuso de poder, as usurpações, a perseguição por delito de opinião, tudo o que afeta o espírito e a liberdade. Ora, toda esta barbárie não é barbárie de tempos primitivos, é barbárie da própria civilização. Deste modo, é preciso retocar a imagem de Voltaire como um otimista ingênuo do progresso.

Voltemos agora ao Cândido. Eu chamaria a atenção para o fato de que, nos contos em geral, os fatores que desencadeiam o curso dos acontecimentos da trama são na maioria das vezes banais a aparentemente sem consequências, mas inauguram uma cadeia de feitos inteiramente desproporcionais às suas causas. No Cândido, bastou um beijo inocente atrás de um biombo para que o personagem fosse lançado nas mais terríveis desventuras. No conto As orelhas do conde de Cherterfield, esta imagem é radicalizada: vemos neste conto que a história dos homens quase sempre depende da digestão e da evacuação. Sidrac, o personagem central deste conto, diz que ao nos aproximarmos de um ministro de estado, é bom saber antes “se ele sofre ou não de prisão de ventre." (VOLTAIRE, 1967a, p. 605).

Sob as imagens grotescas, o que encontramos, o que vemos, é a ideia de que o destino dos homens não é guiado por nenhum desígnio sublime, mas por causas banais, materiais. Deste ponto de vista, a militância filosófica ou literária é, por assim dizer, melancólica. Por várias vezes durante suas peripécias, Cândido exclama: Oh meu deus, que mundo é este?

Mas trata-se de uma melancolia ativa. $\mathrm{O}$ que Candido diz à pequena comunidade ao final do conto é que nosso mundo é este, lugar de males, e não outro. É preciso parar de reclamar e trabalhar.

Vou terminar com uma outra metáfora de Voltaire, numa passagem que também fala do mundo do qual precisamos cuidar, sob o risco de nos arruinarmos todos juntos. A passagem é a seguinte: "O gênero humano é como uma multidão de viajantes que se encontram num barco; uns estão na proa, outros na popa, vários estão na ponte do navio e na quilha e no porão. O barco faz água por todos os lados, a tempestade é contínua: passageiros miseráveis que serão todos engolidos! Será possível que, ao invés de darmos uns aos outros a ajuda necessária que aliviaria a travessia, tornemos a nossa navegação terrível? Mas, este aqui é nestoriano, aquele outro é judeu; ali está um que crê num Picard, outro num nativo de Islebe; eis uma família de ignícolas; lá estão os muçulmanos, a quatro 
passos estão os anabatistas. Ah! Que importam suas seitas? É preciso que eles trabalhem para calafetar o navio, e que cada um, ao assegurar a vida de seu vizinho por alguns momentos, assegure também a sua. Mas eles brigam e perecem." (VOLTAIRE, 1965, pp. 846-847). Diriam os leitores: é melancólico!

Aliás, desde Aristóteles, passando por Ficino e Burton, a figura do melancólico excepcional e ativo mostra que em princípio, não há incompatibilidade entre e melancolia e a vida ativa (FERREIRA DE PAULA, 2008, pp. 53-70).Voltaire-Candide é um melancólico militante. Personagens de seus diálogos filosóficos, que de certa forma são porta-vozes do autor, exibem os traços das inquietações dos filhos de Saturno. No Diálogo Os adoradores, lemos o seguinte: "O homem é mais infeliz do que todos os animais juntos: ele está continuamente à mercê de dois flagelos que os animais ignoram: a inquietação e o tédio, que não são senão o desgosto de si mesmo." (VOLTAIRE, 1867-1870, p. 322). As palavras de Martin no conto repetem esta mesma ideia: "O homem nasceu para viver nas convulsões da inquietude ou na letargia do tédio." (VOLTAIRE, 1967a, p. 235). Trabalhar sem raciocinar é, para Martin, o único meio de tornar a vida suportável. A pequena sociedade se põe então a trabalhar; às vezes Pangloss ainda quer discutir. Cândido ouve, mas diz: Muito bem, mas é preciso cultivar nosso jardim.

\section{Referências bibliográficas}

DESCARTES, R. 1996a. Oeuvres de Descartes. Publiées par C. Adams et Paul Tannery. Paris:Vrin, volume IX. .1996b. Oeuvres de Descartes. Publiées par C. Adams et Paul Tannery. Paris:Vrin, volume VI.

DIDEROT. D., et D'ALEMBERT. 1751-1765. Encyclopédie, ou Dictionnaire raisonné des sicences, des arts et des métiers. Paris: Pergamon Press, ed. Fac-similar.

FERREIRA DE PAULA, M. 2008 Espinosa e a tradição melancólica, Cadernos Espinosanos, São Paulo, XVIII. 
VOLTAIRE, 1965. Mélanges. Paris: Gallimard, Bibliothèque de la Pléiade.

VOLTAIRE. 1867-1870. Oeuvres Complètes. Ed. Moland, Paris: GArnier Frères.

VOLTAIRE. 1967a. Romans et contes. Paris: Gallimard, Bibliothèque de la Pléiade.

VOLTAIRE. 1967b. Dictionnaire Philosophique. Paris: Garnier.

VOLTAIRE. 1990. Essai sur les moeurs. Paris: Garnier. 